\title{
Mapeamento participativo aplicado à Estratégia de Saúde da Família: a experiência em Santo Amaro - BA
}

\author{
Participatory mapping applied to the Family Health Strategy: the experience in Santo \\ Amaro - BA - Brazil
}

Isabel Cristina Moraes ${ }^{1}$, Shanti Nitya Marengo ${ }^{2}$, Gustavo Luís Schacht ${ }^{3}$ e Débora Santos Passos ${ }^{4}$

1 Universidade Federal do Recôncavo da Bahia, CCAAB, Cruz das Almas, Bahia, Brasil. isabelmoraes@ufrb.edu.br ORCID: https://orcid.org/0000-0002-5686-0208

2 Universidade Federal do Recôncavo da Bahia, CCAAB, Cruz das Almas, Bahia, Brasil. shanti@ufrb.edu.br ORCID: https://orcid.org/0000-0003-0669-0500

3 Universidade Federal do Recôncavo da Bahia, CCAAB, Cruz das Almas, Bahia, Brasil. schacht@ufrb.edu.br ORCID: https://orcid.org/0000-0002-7536-6280

4 Universidade Federal do Recôncavo da Bahia, CCAAB, Cruz das Almas, Bahia, Brasil. deborapassos00@gmail.com ORCID: https://orcid.org/0000-0003-2979-859X

Resumo: O acesso a geolocalização em smartphones e tablets tem apontado seu uso potencial no levantamento de dados georreferenciados e como ferramenta de mapeamento replicável por usuários não-especialistas. O objetivo deste artigo é apresentar a experiência do mapeamento participativo dos territórios de ação das equipes de Estratégia de Saúde da Família (ESF) do município de Santo Amaro (BA) com recursos de GPS/GNSS (Global Positioning System/Global Navigation Satellite System) e imagem de satélite do Google Earth, no aplicativo Map Marker. Neste trabalho, são apresentados os aspectos da percepção e transcrição dos elementos espaciais no processo de digitalização e atualização cartográfica destes territórios. Foram realizadas oficinas nas 17 unidades básicas de saúde (UBS) a fim de cartografar os territórios de atuação - microáreas - dos 104 Agentes Comunitários de Saúde (ACS). Das 17 UBS, 10 apresentavam algum produto cartográfico. Esses produtos pré-existentes contribuíram para a correspondência espacial entre o território e as imagens de satélite. A identificação das microáreas foi satisfatória, porém, o maior desafio foi a vetorização das poligonais. Apesar disso, em cada equipe houve ao menos um profissional que se destacou e foi capaz de reproduzir a metodologia sem um mediador. O uso das tecnologias geoespaciais aplicadas ao mapeamento em saúde mostrou-se viável para a área de estudo, e reforça a importância do treinamento para a autonomia dos atores sociais e a democratização desses recursos nas estratégias em saúde pública. A obtenção destas bases cartográficas deve subsidiar à espacialização de doenças registradas na atenção básica bem como à gestão de saúde do município.

Palavras-chave: Geografia da Saúde. Sistema Único de Saúde. Geotecnologias. Aplicativo de celular. Mapeamento Colaborativo.

\begin{abstract}
The access to geolocation on smartphones and tablets has pointed to its potential use in the survey of georeferenced data and as a mapping method replicable by non-specialist users. The objective of this article is to present the experience of the participatory mapping on the action territories of the Family Health Strategy (ESF) teams in the municipality of Santo Amaro (BA) with GPS/GNSS (Global Positioning System / Global Navigation Satellite System) resources and Google Earth satellite image, in the Map Marker application. In this work, aspects of the perception and transcription of spatial elements in the process of digitalization and cartographic updating of these territories are presented. Workshops were held in the 17 Basic Health Units (UBS) in order to map the territories of operation - micro-areas - of the 104 Community Health Agents (CHA). In this work, it's presented aspects of perception and transcription in the process of digitalization and cartographic updating. Of the $17 \mathrm{UBS}, 10$ had some cartographic product. These pre-existing products contributed to the spatial correspondence between the territory and the satellite images. The identification of the micro-areas was satisfactory, however, the biggest challenge was to vectorize the polygonal. Despite that, in each team there was at least one professional who stood out and was able to reproduce the methodology without a mediator. The use of geospatial technologies applied to health mapping proved to be viable for the study area, and reinforces the importance of training for the autonomy of social actors and the democratization of these resources in public health strategies. Obtaining these cartographic bases should support the spatialization of diseases registered in primary care as well as the municipality's health management.
\end{abstract}

Keywords: Health Geography. Health Unic System. Geotechnologies. Mobile app. Collaborative Mapping. 


\section{INTRODUÇÃO}

A Estratégia de Saúde da Família (ESF) foi estabelecida no processo de reorganização do sistema de saúde e pautado nas diretrizes da atenção básica preconizadas pelo Sistema Único de Saúde (SUS), no Brasil. Inserida no princípio da equidade, a atenção básica fundamenta-se no desenvolvimento de ações de saúde em determinado território, sendo tática prioritária a atuação em nível local (BRASIL, 2012). O vínculo entre os serviços de saúde e a população é incorporado ao papel dos Agentes Comunitários de Saúde (ACS). Integrados às equipes das unidades básicas de saúde (UBS), os ACS constituem territórios na medida em que atuam em uma base geográfica definida, as microáreas, e tornam-se atores-chave na operacionalização da ESF em nível local.

O processo de organização e instrumentalização das práticas de saúde pelo Estado, dentro de uma dimensão espacial, é entendido como o reconhecimento de uma situação de saúde a qual conforma um território, enquanto categoria de análise geográfica. A compreensão desse território supera a concepção de um espaço político-operativo do sistema de saúde. Este, não pode ser traduzido como um espaço-palco, não equivale a uma regionalização instrumental (HAESBAERT, 2010) de uma racionalidade planejadora, de caráter burocrático, ligada ao Estado. O território em questão é também um espaço vivido, construído relacionalmente, uma vez que comporta populações específicas, que se relacionam entre si, com suas próprias dinâmicas socioespaciais. Admitir que uma política pública de saúde deve se desenvolver como constitutiva de um território em processo pré-requisita o entendimento das dinâmicas sociais e políticas de um lugar (SANTOS, 2006) e a relação delas com a condição de vida de determinados grupos sociais (MONKEN; BARCELLOS, 2005).

Compreende-se a importância dos ACS, na ESF, aos quais se atribui o papel de mediadores, entre o Estado, responsável por satisfazer as necessidades de saúde da população, e a comunidade, a qual precisa pronunciar suas necessidades de saúde ao Estado. A utilização ótima dos recursos disponíveis depende que esta comunicação se realize com o mínimo de atrito possível. Os ACS são o elo dessa comunicação. Sendo assim, mais do que nunca, os ACS necessitam se apropriar da cartografia em sua dimensão representacional.

Portanto, não é por acaso que os ACS fazem parte da população adscrita, ao mesmo tempo que devem participar da delimitação das suas respectivas áreas de atuação, muitas vezes sem possuir a capacitação técnica e os instrumentos tecnológicos que seriam necessários para tal. Neste ponto se insere a contribuição da proposta metodológica - o mapeamento participativo - a ser descrita neste artigo. Como elucida Goldstein et al. (2013), o mapeamento participativo das áreas de atuação dos ACS surge como alternativa cartográfica à ESF, propiciando um maior envolvimento das equipes no processo de territorialização ${ }^{1}$, e, desta forma, colocandoos também como produtores de uma representação do espaço, a qual lhes auxiliará tanto no sentido de uma atuação estratégica, quanto tática (CERTEAU, 2014). Trata-se de cartografar para compartilhar o mundo, seu território, representando visualmente os eventos em saúde relativos à sua área de atuação, e munindo o gestor de informações espacializadas.

O mapeamento participativo refere-se de forma ampla como método para aquisição e registro de dados espaciais com atores sociais, sendo, portanto, um processo participativo de coleta de informação de determinada localidade, até a elaboração de mapas. Nesta abordagem, o mapeamento participativo é considerado o processo de espacialização de determinado conhecimento, como os territórios de atuação dos ACS. A confecção dos mapas envolve, além da representação gráfica, a apropriação do território pelas equipes da ESF (GOLDSTEIN et al., 2013). Os resultados deste tipo de experiência também estão relacionados a alfabetização cartográfica dos ACS e suas habilidades de leitura do espaço e organização deste pensamento espacial.

Desde a década de 1960, o mapeamento participativo vem sendo utilizado na coleta de informações espaciais para fins de planejamento em comunidades locais. Atrelado ao desenvolvimento dos Sistemas de Informação Geográfica - SIG (GIS - Geographic Information System), entre 1980-1990, o denominado PGIS

\footnotetext{
${ }^{1}$ territorialização é entendido como a demarcação da área de atuação de unidades básicas de saúde, que deve coincidir com a área de abrangência das famílias adscritas a esta unidade (GOLDSTEIN et al., pág. 47, 2013).
} 
- SIG Participativo (Participatory GIS) emerge como ferramenta para servir a grupos minoritários. Este processo de mapeamento participativo surge como atividade capacitadora ao uso de novas tecnologias de informação, para a comunidade representar-se espacialmente (CORBETT et al., 2005).

O mapeamento participativo combinado com SIG fornece um contexto espacial e interativo, e se insere num processo colaborativo de planejamento territorial, com visualização em interface gráfica (TALEN, 2000; SAADALLAH, 2020). O PGIS deve legitimar o conhecimento, a identidade e a necessidade da população local, por meio da combinação entre o especialista em SIG e o conhecimento local. E, diferentemente do mapeamento voluntário e colaborativo (VGI - Volunteered Geographic Information), dedicado ao mapeamento online envolvendo grande volume de dados e acessibilidade de dados abertos, no qual a informação espacial tem diversas finalidades para além de seu propósito original, seguindo um fluxo unilateral, o PGIS aproximase de procedimentos práticos, que incluem a percepção local direcionados a um propósito comum, compartilhando o conhecimento de determinado território (VERPLANKE et al., 2016).

Diversas técnicas vêm sendo utilizadas nas metodologias de mapeamento participativo, desde a elaboração de desenhos rudimentares e croquis, até o uso de elementos da cartografia digital e recursos de GPS (ARAÚJO et al., 2017). Os mapeamentos participativos tradicionais, feitos à mão, no chão ou no papel, reúnem recursos de fácil acesso (papel, lápis/caneta etc.), e, portanto, são bastante democráticos. O principal desafio na inserção de recursos tecnológicos no mapeamento participativo é que o uso dos SIGs (Sistemas de Informação Geográfica) e GPS (Global Positioning System) não devem desempoderar os mapeadores, pelo predomínio dos conhecimentos do mediador. Para que isso não ocorra, deve ser parte da tarefa do facilitador mediar os conhecimentos tecnológicos, através, por exemplo, de um período de treinamento (CHAMBERS, 2006). A técnica do mapeamento participativo associado a SIG,

deve ser precedida por uma mínima capacitação sobre territorialização e alfabetização cartográfica. As limitações e potencialidades do método podem ser convertidas em recomendações para o desenvolvimento de um protocolo pelas instâncias do SUS para a elaboração de mapas participativos georreferenciados, com a presença de agentes facilitadores na orientação e no trabalho de alfabetização cartográfica (GOLDSTEIN, 2012, p.58).

A cartografia envolve a noção de princípios básicos da linguagem cartográfica, e também, a incorporação de SIG principalmente por fornecer recursos que envolvem técnicas estatísticas, gráficas e de análise espacial. Esse recurso permite ágil sistematização e tratamento de dados, com potencial para tornar a gestão dos serviços de saúde mais eficientes, e os avanços das tecnologias da geoinformação favorecem sua incorporação no trabalho das equipes de saúde (MARTINUCI, 2019).

Embora o potencial dos SIG no planejamento dos sistemas de saúde seja inegável, sua implementação demanda reflexões quanto às metodologias disponíveis para sua operacionalização (FOLEY et al., 2002) e esforços para a instrumentação de pessoal e para a democratização de ferramentas tecnológicas, que devem superar iniciativas isoladas (BARCELLOS; RAMALHO, 2002; GHOSE, 2001). O acesso desigual ao SIG pode reforçar as desigualdades sociais e geográficas dos atores sociais. Assim, os usuários de SIG devem ser mais ativos nas relações entre essas tecnologias digitais e a sociedade. Por sua vez, as tecnologias de informação geográfica, que incluem a aquisição de dados por GNSS e sistema de autonavegação integrados a celulares, são portáteis, baratas e simpáticas ao usuário (SHEPPARD, 2008).

O mapeamento online dispõe de ferramentas gratuitas, e oferecem potencial para coleta de dados, que podem ser enriquecidos com componentes espaciais como descrição, fotografia, marcar ou desenhar polígonos. Porém, o maior desafio é a familiaridade com a interface, pois mesmo que o participante já tenha utilizado mapas web para navegação, como Google Maps e Bing Maps, o usuário não cria dados novos, e esta barreira ainda é muito sólida (RZESZEWSKI et al., 2019).

No processo de representação do mundo real, a abstração é um processo cognitivo e pode funcionar como uma ferramenta para entender os diferentes níveis de complexidade dos elementos espaciais. Parte do processo de abstração envolve a discretização do espaço, destacando-se a transcrição de conceitos abstratos formalizados para conceitos geométricos (modelos computacionais - ponto, linha e polígono). Ao mesmo 
tempo, a percepção do espaço por seus aspectos cognitivos, depende da vivência e experiencia do observador, para quem a mesma entidade geográfica pode ser percebida de diferentes formas e ter múltiplas representações. Quanto aos níveis de abstração, existem inicialmente a representação conceitual com alto nível de abstração e as entidades são modeladas com base na percepção do usuário; o nível de apresentação, que se preocupa com os aspectos visuais a serem assumidos pelas entidades geográficas; e, o nível de implementação, que se dedica a estruturação de dados e formas de armazenamento, sendo este último mais distante dos modelos mentais do usuário, necessitando níveis de abstração mais elevados (BORGES et al., 2005). Carver et al. (2009) pensam que os conceitos de espaço e lugar da vida cotidiana são abstratos e imprecisos, e o processo de redução desses conceitos à representação em ponto linha e polígono é mais fácil e direta. Porém, Brown et al. (2012) consideram que a adição de objetos (pontos, linhas e polígonos) aumenta a complexidade cognitiva.

$\mathrm{Na}$ linguagem de comunicação gráfica, as projeções, escala e sistema de símbolos são propriedades dos mapas, que correspondem respectivamente às operações cognitivas de forma, através da rotação, redução e abstração (BLAUT, 1969, p. 50 apud OLIVEIRA, 2014, p. 20). O pensamento espacial se desenvolve a partir de conceitos de localização, habilidades para determinar posições, desenhos (ponto de vista), e representações, relativa a posições e referências topológicas (relações de vizinhança), entre lugares e objetos. Assim, os mapas cognitivos ou mentais permeiam conceitos cartográficos como: visão vertical, obliqua e frontal, noções de medidas e proporção, mais princípios de desenho gráfico. Por sua vez, as representações cartográficas podem ser desenhos, mapas, croquis, fotografias aéreas, imagens de satélite, diagramas etc. (CASTELLAR et al., 2017).

Com o intuito de apresentar experiências de mapeamento participativo a partir de novas tecnologias, Pessoa Colombo (2019) apresentou o uso das tecnologias geoespaciais como forma de prover dados como subsídio a demandas sociais em assentamentos informais. Os atores sociais "se apropriam de instrumentos de cartografia para projetar suas próprias percepções do território" (ibid., p. 64). Este tipo de mapeamento promove "a integração de territórios estigmatizados pela marginalização socioespacial" com potencial para promover "a conscientização de direitos básicos" (ibid., p. 69). O processo de cartografia participativa em SIG, também mencionada como P-SIG, e a facilidade de acesso a tecnologias de geolocalização (principalmente em smartphones) e imagens de satélite do Google Maps, são estratégicos como ferramenta de mapeamento participativo. Como ferramenta de PGIS, Helwitt (2020) utilizou um aplicativo com interface baseada em SIG como suporte a decisão. A tela touchscreen (sensível ao toque) foi apreciada pelos participantes, sendo positiva na qualidade dos aspectos visuais e interativos do mapeamento.

Utilizando recursos de GPS, Fornace et al. (2018) identificaram uma limitação pertinente a coleta de dados espaciais, como da ocorrência de doenças, famílias ou grupos de risco ou mesmo pontos de referência relevantes à condição de saúde, quando da impossibilidade de registro in loco. A coleta de dados espaciais baseadas em dispositivos móveis apresenta-se como solução para aquisição de informações espaciais de forma remota, considerando ainda a dificuldade de acesso a redes de internet, e o uso de imagens de sensoriamento remoto em meio digital mesmo offline. Embora Rzeszewski et al. (2019) tivessem identificado a mesma limitação quanto ao acesso à internet, os autores conseguiram avaliar a carga cognitiva de 30 pessoas realizando tarefas espaciais em plataforma digital. Os autores verificaram que as pessoas mais velhas (com 60 anos ou mais) gastaram mais tempo para executar algumas tarefas, mas esse efeito desapareceu durante o experimento. $\mathrm{O}$ grupo de pessoas mais velhas percebia as tarefas como mais difíceis, mas, na verdade, a dificuldade se refletiu na interface em si, e não na tarefa, e o desempenho desse grupo sugeriu maior familiaridade espacial com as áreas dos mapas. As pessoas sem contato prévio com essas tecnologias não apresentaram desempenho inferior. E particularmente, os recursos de zoom, favoráveis a maior precisão da coleta de dados, foram utilizados com mais frequência pelo grupo mais jovem.

Na comparação de procedimentos metodológicos de mapeamento participativo aplicados à saúde, Dongus et al. (2007) apontaram que no uso de técnicas manuais em meio analógico, os participantes puderam acomodar diferentes habilidades, com "mapas esboços" adaptados às suas referências e preferências pessoais. Neste estudo, apenas alguns participantes ficaram confortáveis com o uso de fotografias aéreas impressas. Porém, este recurso foi o mais adequado na elaboração de mapas formalizados, e foi traduzido como técnica complementar na verificação e correção de esboços. As fotografias aéreas permitiram uma cobertura espacial 
abrangente, de rápida interpretação, requerendo habilidades técnicas mínimas. Demonstrando também o uso de imagens de sensoriamento remoto na redução da complexidade cognitiva do mapeamento, Nascimento et al. (2012) utilizaram imagens do satélite Quickbird na escala de 1:30.000 impressas em papel tamanho A1 como elemento norteador do mapeamento participativo das microáreas do município de Conde-PB. As autoras evidenciaram que as imagens de satélite em cor verdadeira (mundo real) favoreceram a percepção dos locais. Entretanto, afirmam que em função da escala fixa da impressão houve dificuldade de reconhecimento das áreas de interesse. A disponibilização dessas imagens em meio digital (notebook) possibilitou o uso do recurso de zoom, chegando a uma escala de 1:2.000, imediatamente reconhecidas pelos ACS.

E, embora os mapeamentos participativos em meio analógico possibilitem maior liberdade quanto ao processo criativo (CHAMBERS, 2006), como a elaboração de simbologias na composição da legenda, as tecnologias espaciais em dispositivos móveis e SIG podem favorecer o processo de entrada e integração dos dados, de forma fácil, prontamente padronizada e disponibilizada em camadas digitais e/ou imagens (VAJJHALA, 2005). Neste aspecto, é valido considerar que o mapeamento participativo com geotecnologias não deve restringir a participação do usuário, e pode contribuir na sistematização da coleta de dados entre diferentes grupos, a fim de atender a demandas locais.

Deste modo, os smartphones e tablets tornam-se uma ferramenta atraente, a considerar sua ampla difusão, a tecnologia GNSS disponível, e a facilidade de acesso dos mapeadores. Nesse sentido, este artigo tem como objetivo apresentar a experiência do mapeamento participativo com uso de tecnologias de geolocalização em dispositivos móveis para cartografar os territórios de ação das equipes de ESF no município de Santo Amaro, Bahia. Esta proposta metodológica surge da necessidade de obtenção de bases cartográficas digitais das microáreas como suporte à espacialização das doenças registradas na atenção básica e subsídio à gestão de saúde do município. Neste trabalho são apresentados os aspectos da percepção e transcrição dos elementos espaciais no processo de digitalização e atualização cartográfica destes territórios, bem como na identificação de referências espaciais diversas, de interesse da comunidade local.

\section{ABORDAGEM METODOLÓGICA}

O uso da tecnologia de geolocalização em dispositivos móveis para o mapeamento participativo dos territórios de atuação dos 104 ACS que compõem as equipes da ESF do município de Santo Amaro (BA) foi proposto como ferramenta considerando a limitação de recursos técnicos, como a ausência de equipamentos receptores GNSS, e a capacidade de coletar e integrar as informações espaciais das microáreas, em formato digital, de forma sistematizada para todo o município.

Para a execução do mapeamento junto aos ACS, foi adotado o aplicativo Map Marker, habilitado para uso de recursos de geolocalização (GPS/GNSS), de interface simples e disponível para download gratuito. A aquisição dos dados espaciais em meio digital foi objetivada pela sistematização da coleta, acompanhada pela facilidade de integração, atualização e compartilhamento dos dados georreferenciados entre os atores envolvidos. Observou-se também as vantagens quanto à portabilidade e possibilidade de acesso e edição das informações, digitalizadas e virtualizadas, pelo ACS de seu smartphone. Esta possibilidade torna-se interessante quando se percebe o quanto seu território de atuação pode ser dinâmico, e, portanto, é capaz de conformar mudanças frequentes que se refletem tanto no processo saúde-doença, quanto nas dinâmicas socioespaciais da comunidade.

$\mathrm{Na}$ interface do aplicativo Map Marker as imagens de satélite do Google Earth foram habilitadas como plano de fundo, e previamente carregadas para o uso offline. Complementar ao recurso de GPS/GNSS, as imagens de sensoriamento remoto em meio digital tornaram-se uma alternativa para evitar custos de impressão, e pela agilidade na visualização das microáreas. Esse processo incluiu o reconhecimento dos espaços limítrofes e das áreas não acompanhadas pelos profissionais de saúde, denominadas áreas descobertas. Também, a interface digital e a manipulação das imagens com recursos de zoom promoveram a "flexibilização" da escala enquanto noção de proporcionalidade dos aspectos visuais da imagem.

A proposta de oficinas de trabalho foi a estratégia de cunho prático para a valorização da participação dos ACS, considerando o envolvimento efetivo desses atores sociais, fundamental na metodologia 
participativa. A capacitação e instrumentalização dos ACS foi pensada dentro destas práticas, por meio de treinamento na aquisição de dados espaciais no Map Marker como ferramenta de autonomia e empoderamento desses profissionais no processo de territorialização.

Diversos autores discutem metodologias participativas em saúde por meio da proposição de atividades práticas ou oficinas, estabelecidas em fases ou etapas, como Goldsteim et al., (2013), Burke et al. (2005) e Araújo et al. (2017). Bezerra et al. (2017) apresentam uma metodologia participativa de territorialização conduzido em oficinas desenvolvidas em momentos: apresentação; avaliação da percepção do território; construção do processo de territorialização; e estratégias de planejamento. Canal et al. (2018) conduziram o mapeamento participativo em saúde por meio de uma trajetória metodológica de sensibilização e mobilização; levantamento cartográfico; atividade de campo; e avaliação e proposição de ações. E especificamente, a elaboração de um mapa participativo em etapas de mobilização; espacialização; e apresentação/discussão do produto gerado.

Para este trabalho foram definidas as etapas metodológicas de mobilização dos atores sociais, realização de oficinas com os ACS, organização e estruturação de dados em SIG e feedback aos participantes e à Secretaria Municipal de Saúde. As etapas metodológicas foram realizadas entre junho e outubro de 2019:

\subsection{Mobilização dos atores sociais (ACS)}

Consistiu na apresentação da proposta de mapeamento participativo junto à Secretaria Municipal de Saúde, e solicitação de apoio para a mobilização dos ACS. Esta etapa envolveu a elaboração e divulgação de um material de apoio para conhecimento prévio da proposta metodológica, apresentando os objetivos do mapeamento, do processo de territorialização e do uso de ferramentas cartográficas, exemplificando a relação entre a visão oblíqua e a vertical em mapas e imagens de satélite. Ao final, este documento ilustrou o potencial do mapeamento das microáreas para o reconhecimento da situação de saúde no contexto geográfico do território de Santo Amaro.

\subsection{Oficinas}

No período de execução das oficinas, foram realizados 19 encontros de mapeamento para as 17 unidades de saúde, sendo 15 unidades compostas por 1 equipe cada, e 2 unidades formadas por 2 equipes. Na área urbana concentram-se o atendimento em 9 unidades de saúde, e 8 unidades localizam-se em comunidades rurais, totalizando 104 ACS que realizam visitas domiciliares regulares, sendo 86\% deste grupo composto por mulheres. Da população de Santo Amaro (BA) estimada em 60.069 habitantes para $2019^{2}$, estima-se que $78 \%$ possuem cobertura pelo acompanhamento dos ACS, na atenção básica. Esses agentes vêm exercendo suas funções há um período entre 17 e 27 anos, e comumente, permanecem atendendo às mesmas microáreas durante longo tempo, acima de 10 anos (informação verbal ${ }^{3}$ ).

As oficinas foram realizadas para cada equipe de saúde, somando no máximo 7 ACS, durante um período do dia, de acordo com a disponibilidade previamente informada pelos coordenadores de cada unidade. Os docentes e discentes da pesquisa atuaram como facilitadores/mediadores no processo de mapeamento. Os dispositivos móveis utilizados foram: 1 tablet e os aparelhos celulares disponibilizados pelos mediadores, ACS e coordenadores de saúde. As oficinas foram subdivididas em fases (Figura 1): a. apresentação, b. diagnóstico (Figura 2), c. espacialização e treinamento (Figura 3), e d. visita de campo.

\footnotetext{
${ }^{2}$ População estimada em 2019 com base no Censo Demográfico do IBGE em 2010.

${ }^{3}$ Informação fornecida pela Secretaria de Saúde do Município de Santo Amaro (BA), em maio de 2019.
} 
Figura 1 - Etapas das oficinas de mapeamento participativo.

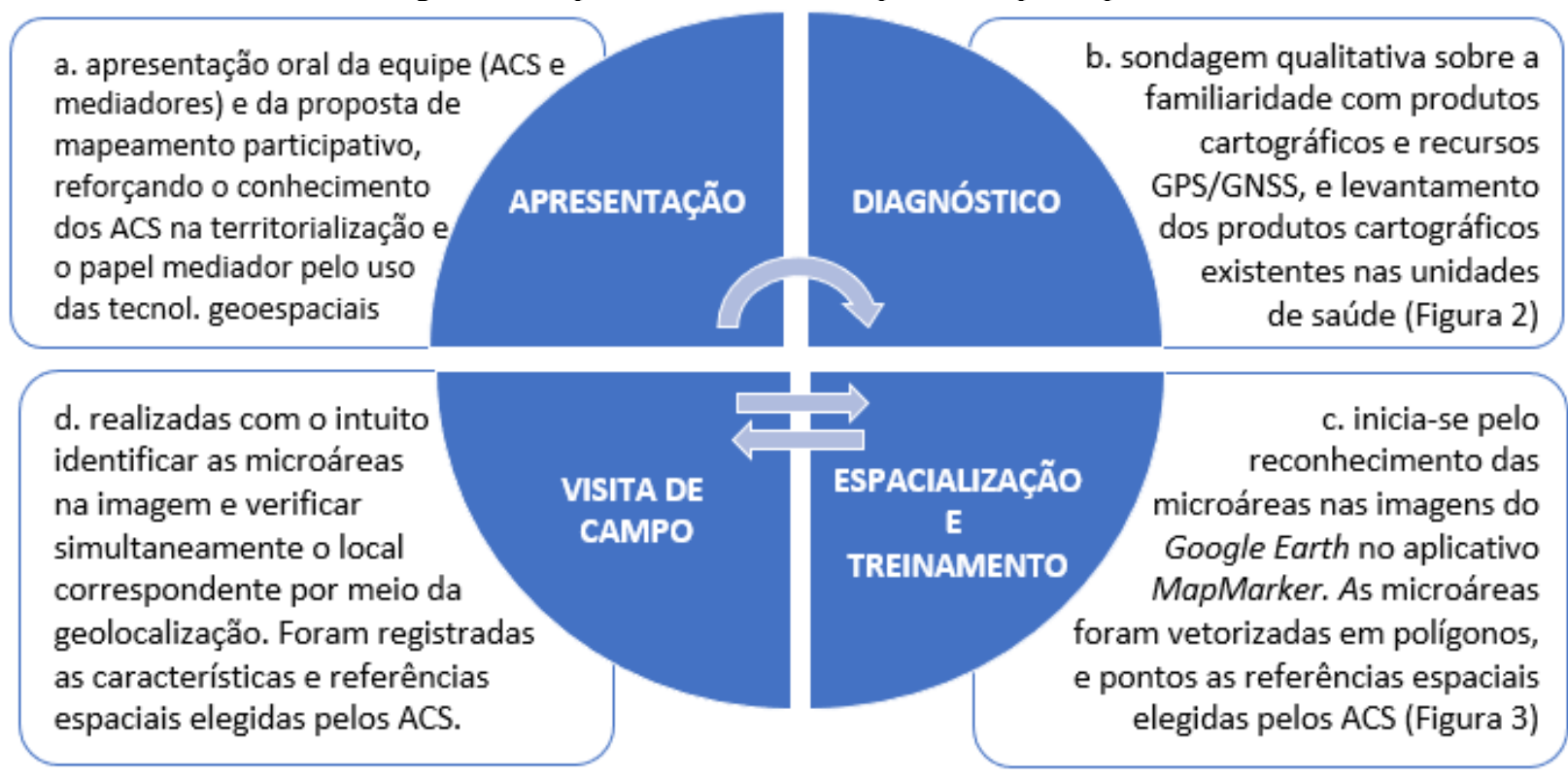

Fonte: Os autores (2021).

Seja na unidade de saúde ou em campo, a espacialização foi realizada na interface digital do Map Marker, que permitiu adicionar representações vetoriais (ponto, linha e polígono). As microáreas foram vetorizadas em linhas ou polígonos, e os pontos foram usados para representar as principais referências espaciais apontadas pelos ACS como importantes, que incluíram pontos comerciais, igrejas, despejo de lixo, entre outros. O processo de vetorização foi realizado tanto pelos ACS, com apoio dos mediadores, quanto pelos próprios mediadores, a depender da familiaridade de cada participante com a interface do aplicativo.

Figura 2 - Exemplo das equipes da USF de Sinimbu (a) e da USF de Pedras (b) durante a fase diagnóstica das oficinas, onde os ACS apresentaram os produtos cartográficos pré-existentes. Enquanto os ACS se debruçam sobre os croquis, no chão, demonstram seu grau de apropriação da perspectiva vertical da paisagem na qual trabalham. Os registros referem-se as oficinas realizadas em 16/07/2019 (a) e 21/10/2019 (b).

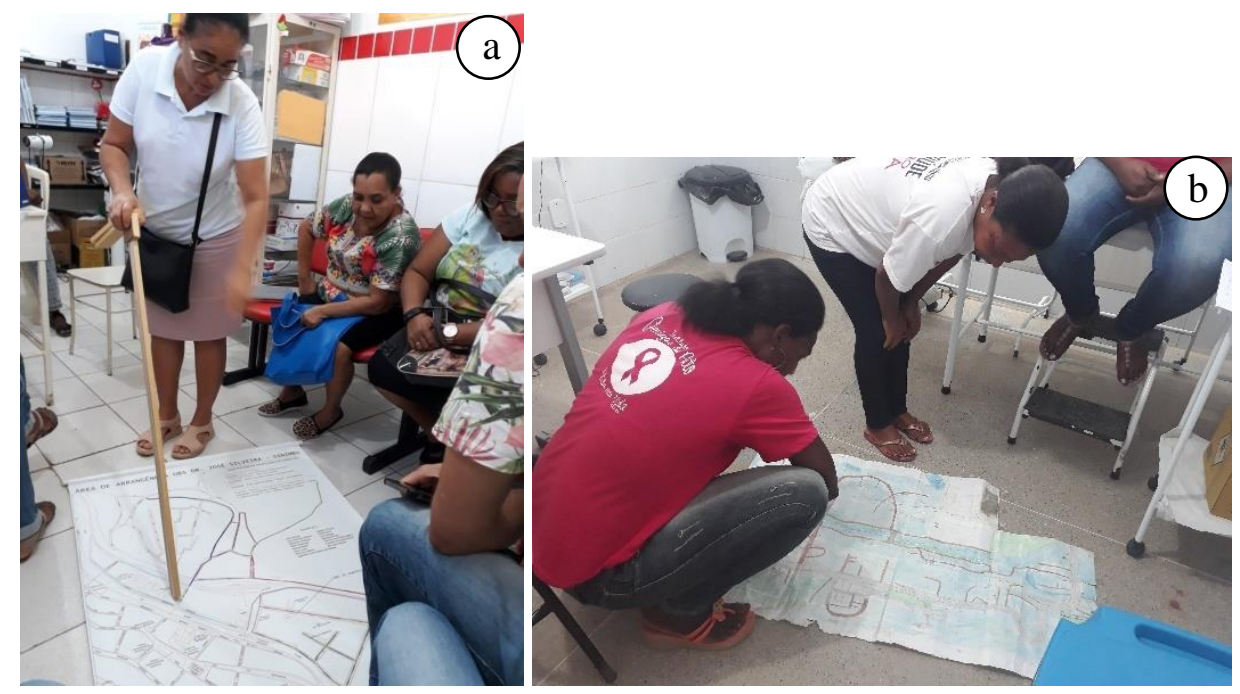

Fonte: Os autores (2021). 
Figura 3 - Exemplo da fase de Treinamento e Espacialização com recursos de geolocalização em dispositivos móveis. Nesta etapa, os ACS realizam o reconhecimento e identificação dos seus territórios, de forma interativa com recursos de tela touchscreen para a visualização em diferentes escalas e manipulação das imagem de satélite; e, sequencialmente, os ACS e/ou os mediadores realizam a vetorização das microáreas com entidades geográficas de múltiplas representações:

(a) USF de Sacramento, em 11/07/2019; (b) USF de Acupe, em 18/07/2019; (c) microáreas vetorizadas no Tablet, na USF de Acupe; (d) USF de Nova Conquista, em 07/10/2019; e (e) USF de Tanque de Senzala, em 09/10/2019.
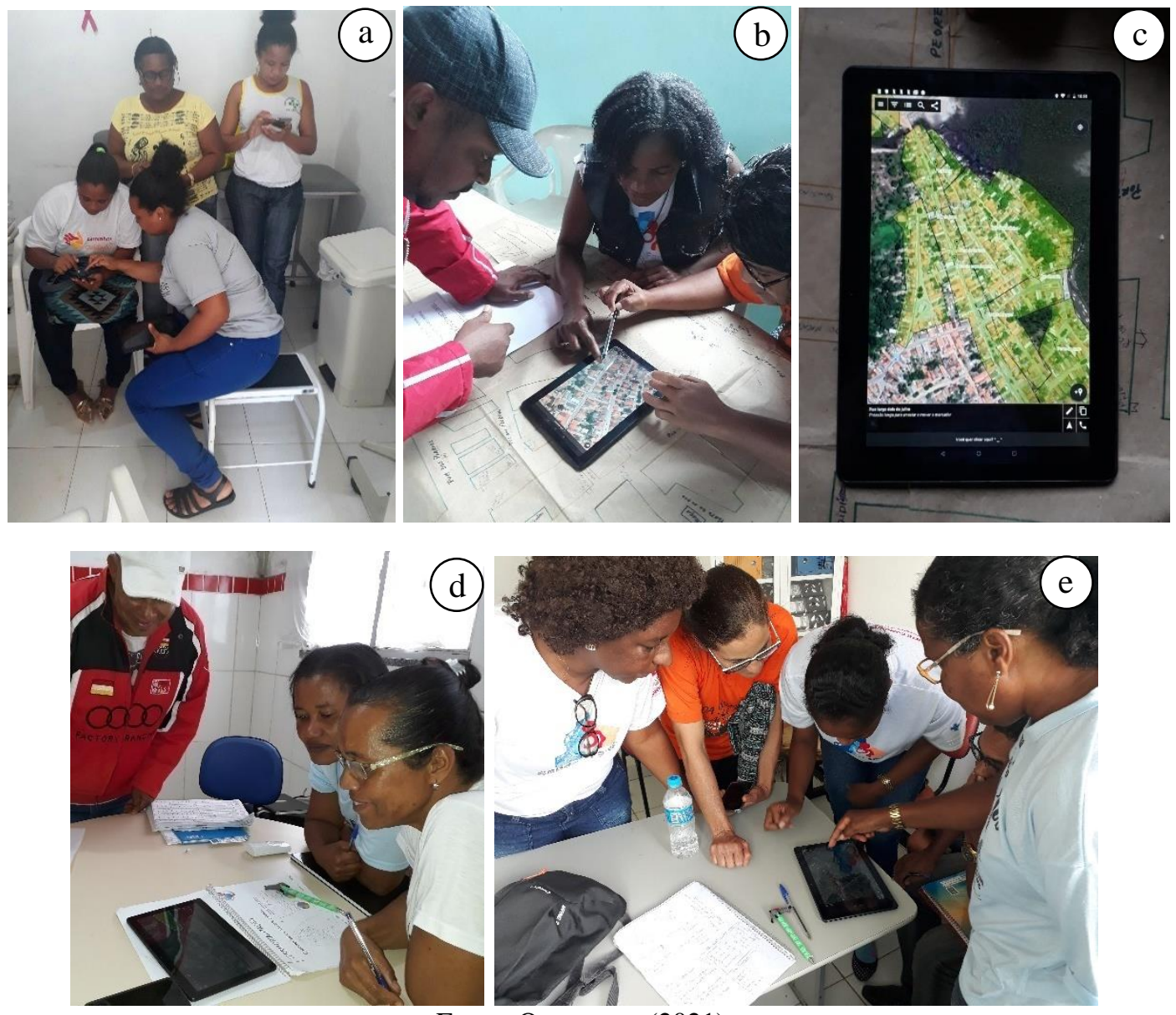

Fonte: Os autores (2021).

Nesta etapa, faz-se considerações aos instrumentos de pesquisa, conforme Oliveira (1992 apud MONKEN, 2008, p. 154-160): o trabalho de campo como "um palco privilegiado de manifestações e interações" entre pesquisadores e grupo estudado; o mapeamento enquanto elemento concreto do espaço por intermédio de sinais que facilitam a síntese interpretativa, sendo o mapa um produto da prática social; e as fotografias como instrumento estratégico no reconhecimento dos objetos e ações do território.

\subsection{Organização e estruturação de dados em SIG}

Tratamento dos produtos gerados pelo mapeamento pela equipe especialista. Em ambiente de SIG (ArcGis 10.5®), os dados georreferenciados adquiridos no Map Marker em formato $\mathrm{kml}$ foram convertidos para o formato shapefile. Mantendo a originalidade das informações apontadas por cada ator, houve a verificação e adequação das sobreposições entre as microáreas, e exclusão das poligonais duplicadas. No que tange a organização da tabela de atributos, cada polígono foi identificado pelo código da microárea, nome do ACS, unidade de pertencimento e data da oficina. Os pontos de referência foram categorizados em: ambiental, escolar, centro religioso, ocupação, ponto comercial, referência espacial, USF e área descoberta. Esse procedimento teve por objetivo a estruturação de um banco de dados georreferenciados, utilizando o mesmo software ArcGIS 10.5. 


\subsection{Feedback}

Esta etapa refere-se ao retorno dos resultados oriundos do mapeamento participativo para os ACS e a Secretaria de Saúde. Neste sentido, tem-se a elaboração de produtos cartográficos para cada unidade de saúde, e o compartilhamento de todas as informações em meio digital, através de um link que pode ser acessado por diversos aplicativos, como Google Maps, Google Earth, GPS Essential, Map Marker e outros. Este procedimento apresenta os territórios de todas as unidades, e que podem ser constantemente atualizados pelos profissionais de saúde.

\section{RESULTADOS E DISCUSSÕES}

\subsection{Mobilização dos atores sociais (ACS)}

No momento inicial das oficinas foi possível perceber falhas na etapa de mobilização. A desinformação com relação a atividade que seria realizada revelou dificuldades de organização do principal agente mobilizador, ou seja, a própria administração municipal. O desconhecimento do material de apoio e do propósito do mapeamento por parte dos ACS foi ajustado com a explicação dada pelos facilitadores (fase de apresentação). Entende-se que em trabalhos participativos muitas vezes é necessário se adaptar a cada grupo ou contexto.

\subsection{Oficinas}

As oficinas foram conduzidas com base nas considerações que Chambers (2006) denominada de "comportamentos e atitudes" na realização do mapeamento participativo com recursos de SIG. O primeiro comportamento do facilitador para esta tarefa é acreditar nos conhecimentos do território e na capacidade de mapear dos profissionais. As implicações éticas envolvem considerar o tempo despendido pelos participantes, ser claro quanto às expectativas dos resultados, coletar informações sem expor ou comprometer os atores envolvidos, e retornar os resultados esperados.

É válido ressaltar as considerações metodológicas de mapeamento participativo dadas por Burke et al. (2005), de uma aproximação de cunho qualitativo na compreensão de fenômenos no processo de territorialização. Nessa perspectiva, foi realizada uma sondagem qualitativa, denominada de etapa 'a', sobre a experiência do uso de GPS em dispositivos móveis pelos participantes. A maioria dos ACS manifestou nunca ter experienciado recursos de GPS/GNSS, e alguns explicitaram não dispor de smartphones e/ou não terem qualquer familiaridade com esses recursos. A familiaridade prévia com tecnologias de informação geoespacial e sistema de navegação por satélite em dispositivos móveis não implica necessariamente no aumento do nível de percepção espacial dos mapeadores e nem na qualidade do mapeamento. De acordo com Speake et al. (2012), apesar dos aspectos positivos quanto a interatividade dos sistemas de navegação por satélite em dispositivos, o predomínio do uso dessas novas tecnologias em detrimento dos mapas tradicionais gera certa desconexão geográfica e espacial dos usuários. Ishikawa (2019) mostrou que usuários frequentes com o uso de tecnologias geoespaciais apresentaram efeitos negativos do pensamento espacial, enquanto usuários de mapas analógicos, juntamente com suas experiências individuais, eram mais sensatos quanto ao senso de direção e rotação do ponto de vista.

Ainda na etapa 'a', alguns ACS também demonstraram algum grau de desconfiança em relação a atividade, pois levantaram a possibilidade de a nova tecnologia retirar deles a autoria e o controle da informação que detinham: a representação do espaço no qual trabalham. Estas manifestações ficaram aparentes no trabalho prático onde se pode observar a dificuldade de parte dos agentes em relacionar os atributos observados em uma visão zenital. O relativo desconhecimento das tecnologias que envolvem estes aparelhos de GPS/GNSS, em especial a familiaridade com a interface gráfica, é somado a dificuldades de uma baixa alfabetização cartográfica. Esta dificuldade também se materializou na observação das imagens em diferentes escalas, conceito fundamental para uma adequada representação de seu território de atuação. Matsumoto e 
D'Andrea (2019) constatam um abismo quando tentam relacionar em seus levantamentos a noção de escala e saúde, assumindo que se trata de um assunto pouco debatido na área da saúde.

O incentivo à participação do ACS ocorreu através da fala do mediador, se colocando apenas como um colaborador cujo objetivo é contribuir para tornar suas práticas mais eficientes e capazes de alcançar resultados mais precisos e adequados, reforçando o papel deles como detentores principais do conhecimento do território e de suas fragilidades. Procurou-se estabelecer entre o mediador - um pesquisador/discente da universidade - e o ACS uma relação horizontal de troca, na qual um contribuiria com seu conhecimento técnico acerca da elaboração de uma representação do espaço para fins estratégicos - o mapa - e o outro contribuiria com seu conhecimento empírico construído a partir da sua experiência prática no espaço vivido, ambos investidos do objetivo de contribuírem para um sistema de saúde mais efetivo.

No diálogo inicial das oficinas, denominada etapa diagnóstica - etapa 'b' - todas as equipes de saúde relataram já ter elaborado mapas de suas áreas em meio analógico, solicitados pelo município como ferramenta de planejamento e gestão das práticas de saúde. Em geral, foram desenvolvidos por pelo menos um ACS de cada equipe, ou por metodologias participativas dos ACS e das coordenações. Em 10 unidades de saúde foram encontrados os mapas analógicos, sendo 8 elaborados à mão e 2 com elementos manuais sobrescritos em uma base cartográfica digital impressa. Nas unidades que possuíam mapas impressos, os mediadores os utilizaram para interpretar a correspondência espacial com os elementos visuais das imagens de satélite, e participativamente, transporem essas informações para as bases digitais do aplicativo, exemplificados pelas Figuras 4,5 e 6.

Figura 4 - Fragmento do croqui da USF da Caixa D'água e as correspondências espaciais reconhecidas no esboço (mapa analógico) e na imagem de satélite (imagem digital), onde são identificadas as mesmas feições mapeadas, conectadas pelas setas amarelas: (a) Via férrea; (b) Lagoa mapeada no esboço, e identificada como Ảrea risco/Área alagada; e

(c) Área de risco em vermelho (analógico), descrita no mapeamento como área de despejo de lixo e entulho, correspondendo a área identificada com um círculo amarelo na imagem de satélite.

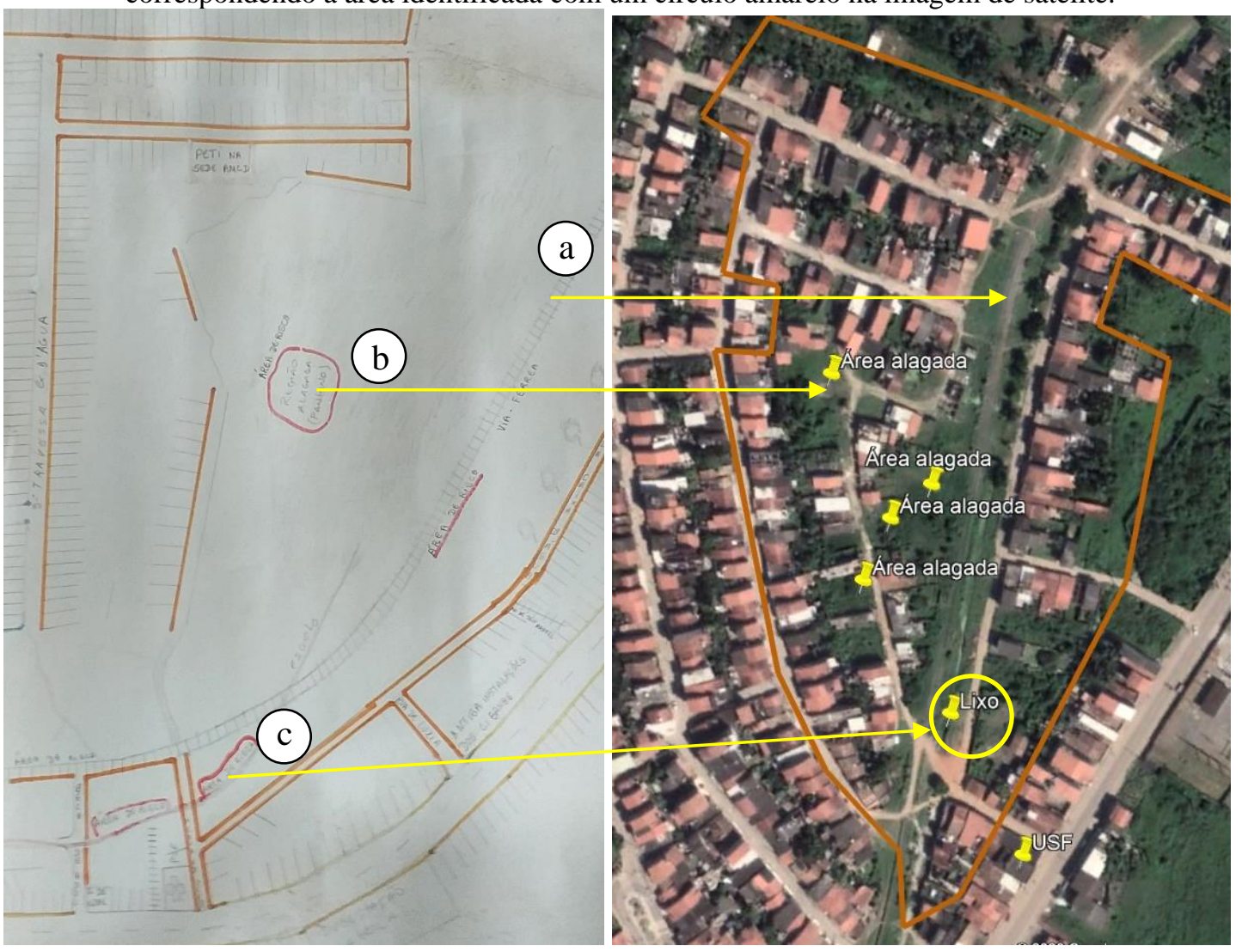

Fonte: Os autores (2021). 
Figura 5 - Fragmento do mapa analógico afixado na parede do USF do Trapiche de Baixo e as correspondências espaciais das feições mapeadas. Durante o mapeamento houve a intervenção manual dos ACS com a intenção de registrar referências espaciais que consideravam relevantes: (a) o rio Subaé, elemento que configura a paisagem urbana; e (b) o campo de futebol. O mapeamento desses espaços remete à importância dos aspectos ambientais e das interações

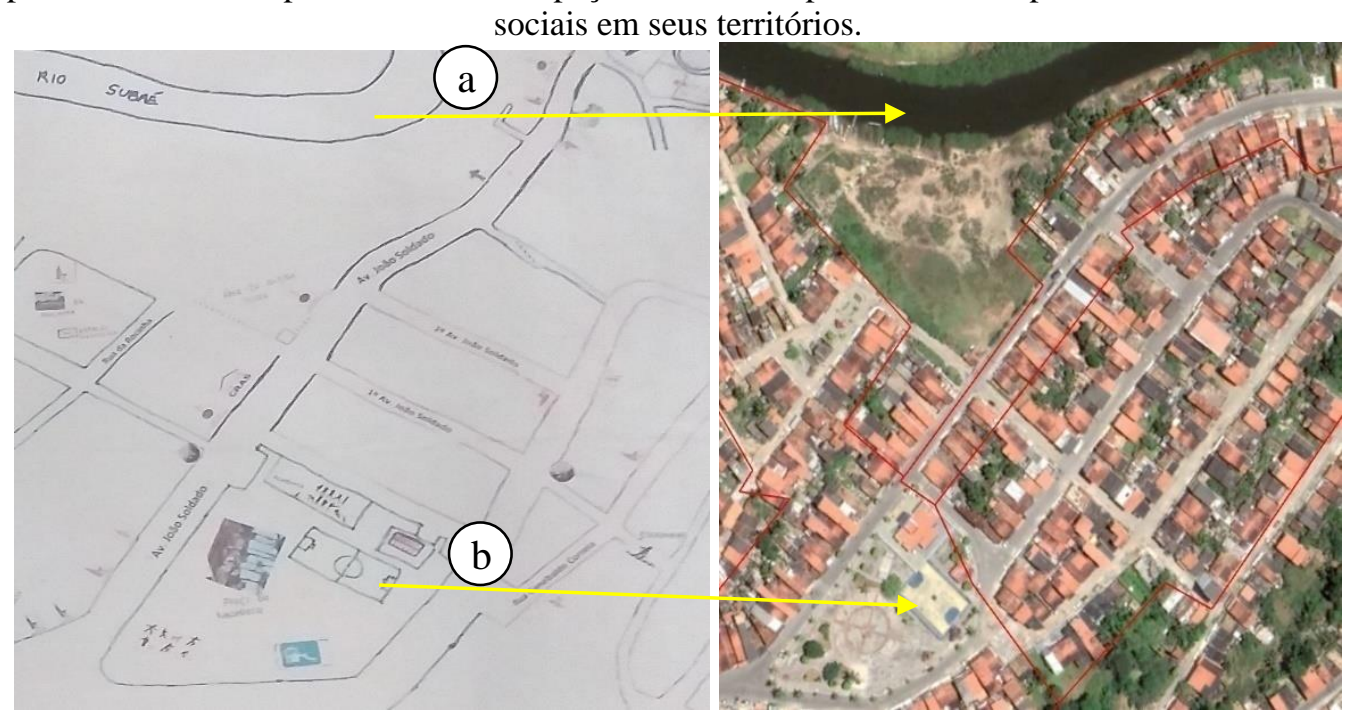

Fonte: Os autores (2021).

Figura 6 - Comparação das metodologias de mapeamento: (a) fragmento do esboço de mapa da USF do Derba; e (b) a correspondência espacial das microáreas sobrepostas à imagem de satélite. As microáreas são representadas espacialmente por linhas e polígonos de cores semelhantes na imagem do croqui (a) e na imagem digital (b).

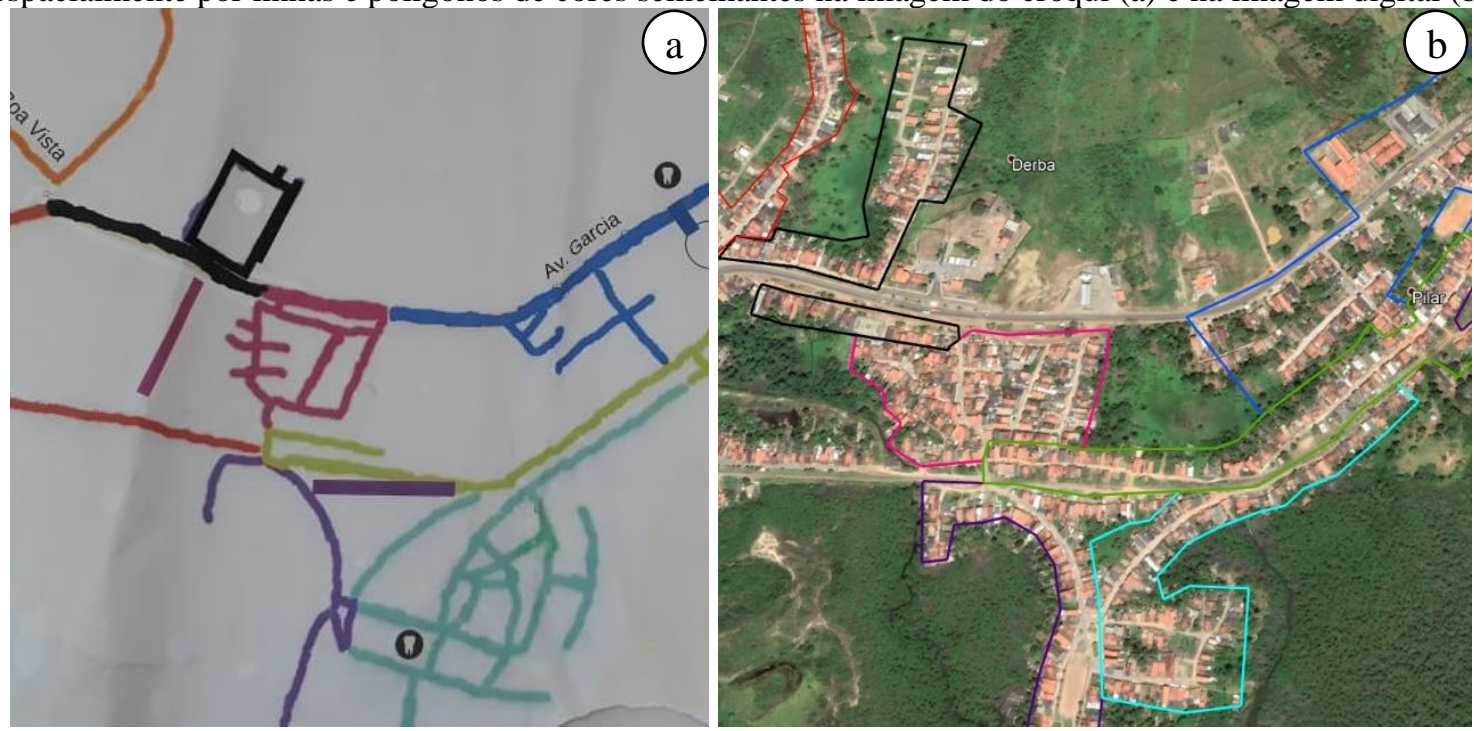

Fonte: Os autores (2021).

Durante a experiência de espacialização e treinamento - etapa 'c' - foi possível perceber dois elementos fundamentais para o mapeamento participativo: o cotidiano de atuação dos ACS nos referidos territórios, seja enquanto profissionais, seja como pertencentes àquele grupo social; e a interpretação das imagens de satélite (cor verdadeira) como registro fidedigno das áreas de interesse. É interessante observar como as imagens dos mapas analógicos demonstram indiretamente a qualidade híbrida do ACS, enquanto agente público de saúde e, ao mesmo tempo, indivíduo pertencente à comunidade onde atua. Os mapas analógicos, construídos pelos ACS, se realizam como representações do espaço vivido da comunidade, nos quais marcos simbólicos significativos do lugar estão indicados, um procedimento que aliena parcialmente o mapa para a racionalidade instrumental estatal, mas o torna adequado à ação dos ACS, indivíduos que, por pertencerem aos lugares onde atuam, conhecem bem as relações e os marcos simbólicos presentes na paisagem destes espaços.

Para Correia (2003) citado por Fonseca et al. (2010), o espaço pode ser percebido por cada um de maneira singular, de acordo com sua história de vida ou experiências individuais. $\mathrm{O}$ autor comenta ainda que 
a cultura vivenciada pelo ator insere em cada um valores e comportamentos que influenciam na absorção de informações gerais e espaciais. É dizer que, cada ator participante do mapeamento participativo aponta informações de referências locais que são diferentes dos demais. Isso fica claro em campo, onde alguns ACS se preocupam em apontar detalhadamente referenciais ambientais que afetam negativamente a saúde, como o fato do rio ser poluído ou haver um acumulo de lixo, enquanto outros apontam predominantemente aspectos como a existência de bares, diagnosticando estes espaços como responsáveis pelo elevado número de casos de alcoolismo. Isso nos confirma que neste processo ninguém melhor que o indivíduo imerso, neste caso os ACS, para representar o lugar.

Fonseca et al. (2010) defendem que a representação do espaço em um material cartográfico passa pelo processo vivido-concebido-percebido, de cada ator. Sendo assim, quanto maior a aproximação e a vivência do ator na área mapeada, melhor o entendimento das relações espaciais ali presentes. O reconhecimento deste espaço de trabalho e a vivência nesta comunidade, desenvolve nos ACS melhores habilidades cognitivas, que são construídas desde seu ambiente escolar. Certamente que estes atores são fundamentais na construção deste processo de mapeamento e seu tempo de exposição no território gera mais detalhes no mapa produzido.

No processo cognitivo de conhecimento das informações espaciais, a leitura e a interpretação de produtos cartográficos dependem da rotação do ponto de vista para uma perspectiva zenital, da alteração na escala e da abstração de um conjunto de símbolos, conforme descrevem Almeida (2014) e Castellar et al. (2017). Nesta perspectiva, as oficinas provocaram intencionalmente algumas discussões sobre a visão vertical, relação de proporcionalidade e escala. Para o reconhecimento das imagens de sensoriamento remoto no aplicativo Map Marker, tratou-se sobre a "transferência" de uma visão oblíqua e tridimensional, para a identificação dos mesmos elementos em uma visão verticalizada e bidimensional. Os recursos de zoom auxiliados pela tela sensível ao toque foram intensamente trabalhados na manipulação da imagem, a fim de proporcionar certa "flexibilidade" na escala e favorecer o reconhecimento dos territórios de atuação dos ACS.

Tal abordagem possibilitou aos ACS a percepção de múltiplas formas e tamanhos dos elementos geográficos. Os recursos utilizados favoreceram ao que Board (1978) denomina de 'navegação' e 'medição' durante a tarefa de leitura de mapas, sendo a primeira associada ao reconhecimento da própria posição e a capacidade de orientar-se, e a segunda relacionada a proporção e noção de escala. Na fase subsequente que o autor denomina de 'visualização', na qual trata-se sobre a verificação empírica do mundo real, evidencia-se que o exercício visual se torna mais exigente quando o mapeador tem poucos conhecimentos sobre o objeto a ser mapeado. De acordo com Speake et al. (2012), o uso das imagens de satélite durante a tarefa de visualização torna o reconhecimento do território mais intuitivo.

A diferença entre a interpretação de um mapa base e uma imagem remete ao grau de abstração empregado nos símbolos. Enquanto a aquisição de informações de forma direta é atribuída às modalidades sensoriais (visual, tátil, olfativa e sinestésica), por meio do contato e da experiência vivida, as fontes indiretas reforçam essas modalidades sensoriais, como é o caso dos recursos visuais de mapas e imagens (DOWNS et al., 2011). Desta forma, a identificação das microáreas e a interpretação das imagens de satélite ocorreram de forma satisfatória. Boa parte dos profissionais demonstrou habilidade para se orientar e reconhecer a própria posição e de lugares e objetos a partir da imagem, identificando de forma intuitiva seus territórios e referências espaciais pertinente a eles. Prontamente, reconheciam espaços mais facilmente identificáveis nas imagens, como praças, campos de futebol, área de vegetação densa e rios.

No que se refere ao processo de demarcação e vetorização das microáreas, houve a participação de um grupo minoritário. Embora tenha sido reforçado com os ACS a liberdade quanto a inserção das geometrias, considerando as múltiplas representatividades dos elementos mapeados, verificou-se que uma das maiores dificuldades foi a adição e edição de linhas e polígonos. Estas observações corroboram com o maior nível de complexidade na criação de feições, aspectos destacados por Borges et al. (2005), Brown et al. (2012) e Rzeszewski et al. (2019). O tempo reduzido mostrou-se como um fator limitante para o treinamento de vetorização digital.

Sequencialmente, a visita a campo - etapa 'd' - era uma iniciativa conduzida pelos ACS. Embora fosse relativamente fácil visualizar as áreas remotas a partir das imagens de satélite nos smartphones e tablet, percorrer as microáreas era um convite aos mediadores. A ida ao campo com os ACS foi um exercício de 
observar, por exemplo, detalhes do contexto geográfico da saúde nas diversas áreas de atuação. Quando se visitou algumas áreas periféricas da cidade os mediadores tiveram a oportunidade de constatar vários elementos mais ou menos temporários na paisagem que poderiam ser representados em mapas digitais, cuja edição fosse mais flexível. No bairro do Pilar, por exemplo, pôde-se notar a existência de vários pontos de alagamento durante a estação chuvosa (Figura 7), assim como pontos de acúmulo de lixo e entulho (que foram encontrados também em outros bairros, o Sinimbu e o Bonfim, por exemplo, como demonstrado na Figura 8). Em outro exemplo, no bairro da Caixa D’Água (ver Figura 9, abaixo) se verificou como as diversas ruas de terra alagavam a ponto de se tornarem habitat de anfíbios e parasitas. Essas informações, uma vez georreferenciadas, poderiam constar em mapas diretamente editáveis pelos ACS, fornecendo informações ao sistema de saúde.

Figura 7 - Bairro do Pilar, pertencente a USF do Derba, situado no setor jusante do rio Subaé, que sofre constante influência das oscilações de maré, devido ao seu deságue na Baía de Todos os Santos - BTS: (a), (b), e (c) apresentam diversos pontos com áreas alagadiças; e (d) deságue de água pluvial e esgoto em córrego - registros de 07/10/2019.

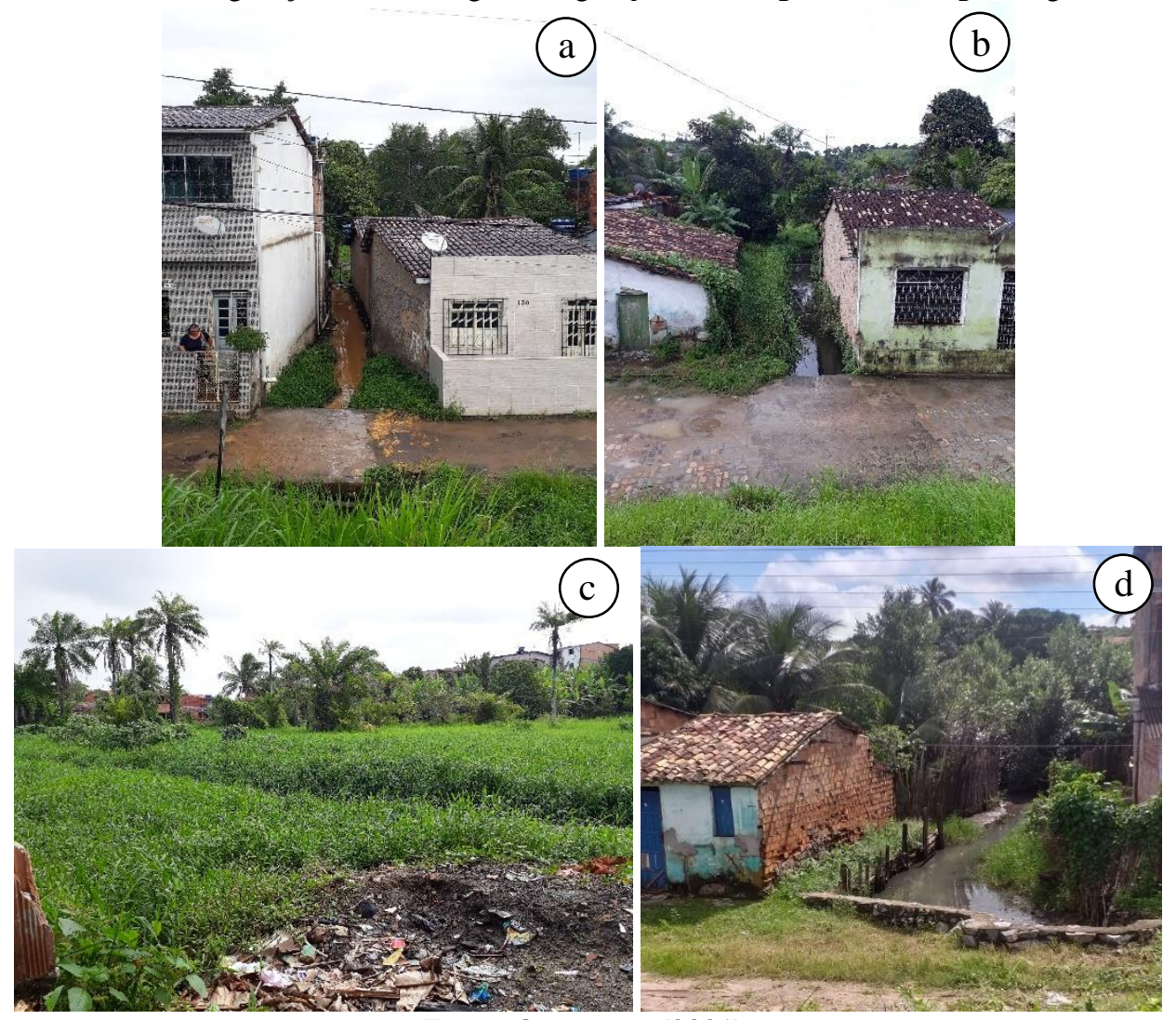

Fonte: Os autores (2021).

Figura 8 - Pontos de acúmulo de entulho e lixo, espacializados digitalmente durante a visita de campo: (a) no bairro do Sinimbu, em 16/07/2019; e (b) no bairro do Bonfim, em 23/09/2019.

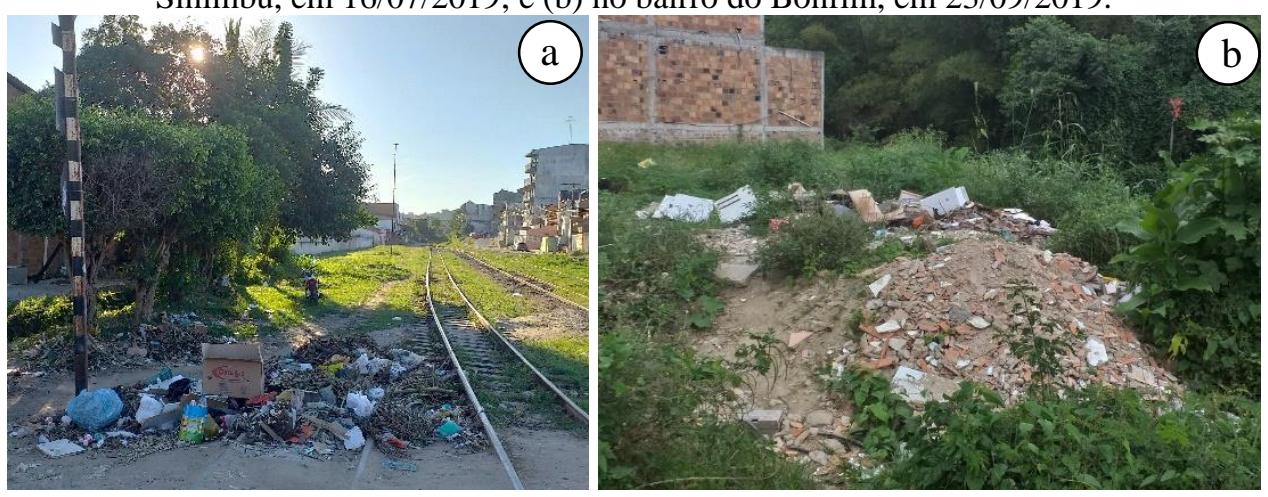

Fonte: Os autores (2021). 
Figura 9 - Pontos de alagamento devido às chuvas, registrados no bairro da Caixa D’Água, em 19/06/2019: (a) terreno alagado, em meio a área residencial; e (b) rua alagada, na qual foram encontrados anfíbios e parasitas.

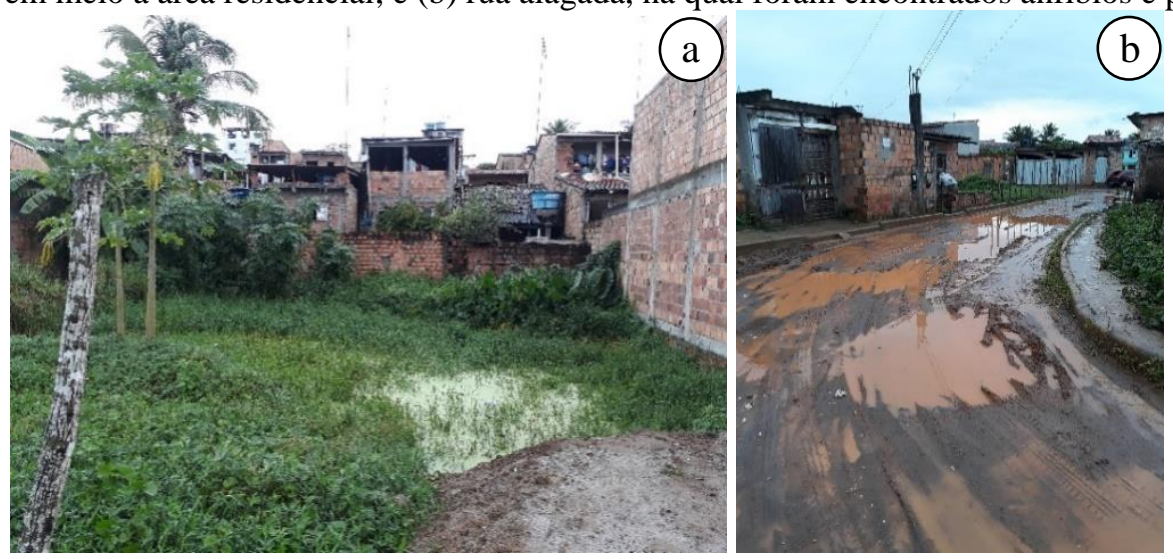

Fonte: Os autores (2021).

A ida ao campo também possibilitou aos mediadores verificar o dinamismo e a sutileza das formas de habitar dos moradores da cidade. Uma residência que, na perspectiva vertical da imagem de satélite, se mostrava unifamiliar, na perspectiva horizontal, no plano da caminhada, se denunciava como uma habitação precária e plurifamiliar, ou seja, compartimentada ilegalmente em vários apartamentos. Especialmente nas áreas urbanas, a verticalização das casas em alguns bairros santo-amarenses evidencia um processo de precarização das condições de moradia. Consequentemente, o aumento significativo das populações acomodadas neste território corresponde a um crescimento da demanda por estes profissionais. Enfim, ir ao campo significou a possibilidade de verificar detalhes, assim como aspectos mais situacionais e circunstanciais que dificilmente seriam apreendidos em uma perspectiva vertical.

A localização espacial a partir de pontos de referência foram bastante distintos no meio urbano e no meio rural. As referências espaciais no meio urbano corresponderam em grande parte a locais já identificados nas bases digitais associadas à imagem de satélite, como igrejas e pontos comerciais. No meio rural, predominavam as referências espaciais empíricas e informais, como casa e fazendas de pessoas específicas. Neste último caso, torna-se ainda mais importante a participação desses profissionais no processo de mapeamento, visto que a informação dependia ainda mais de um conteúdo de pessoalidade comum nas relações interpessoais presentes em núcleos populacionais mais ruralizados.

\subsection{Organização e estruturação de dados em SIG}

A aquisição das informações espaciais nas oficinas foi compartilhada em arquivos digitais do tipo $\mathrm{kml}$ para a sistematização dos dados e elaboração de mapas em SIG. Esta etapa foi realizada por equipe especializada sem a participação dos agentes de saúde. Convertidos para o formato shapefile, cada uma das poligonais correspondentes às microáreas, foram identificadas pelo 'código' da microárea, e acrescentados os campos 'Nome do ACS', 'Equipe, e respectiva 'USF'; os pontos de referência foram categorizados em: ambiental (pontos de entulho, lixo, alagamento, etc.), área descoberta (área sem acompanhamento mensal dos ACS), centro religioso (igrejas, terreiros, etc.), escolar (referência espacial de instituições de ensino), ocupação (inclui aldeia, assentamento, povoado, loteamento e ocupação irregular), ponto comercial, referência espacial (inclui nomes de ruas, becos, travessas, praças e toponímias), e USF, conforme apresentado nas Figuras 10 e 11. 
Figura 10 - Exemplo dos resultado alcançados pelo mapeamento participativo, organizado e estruturado em ambiente de SIG: (a) poligonais das microáreas da USF do Sinimbu, com destaque à USF e a referência espacial categorizada como 'ponto comercial'; e (b) poligonais referente às microáreas da USF de Acupe, e referências espaciais das categorias 'centro religioso', 'ambiental' e 'ponto comercial'.
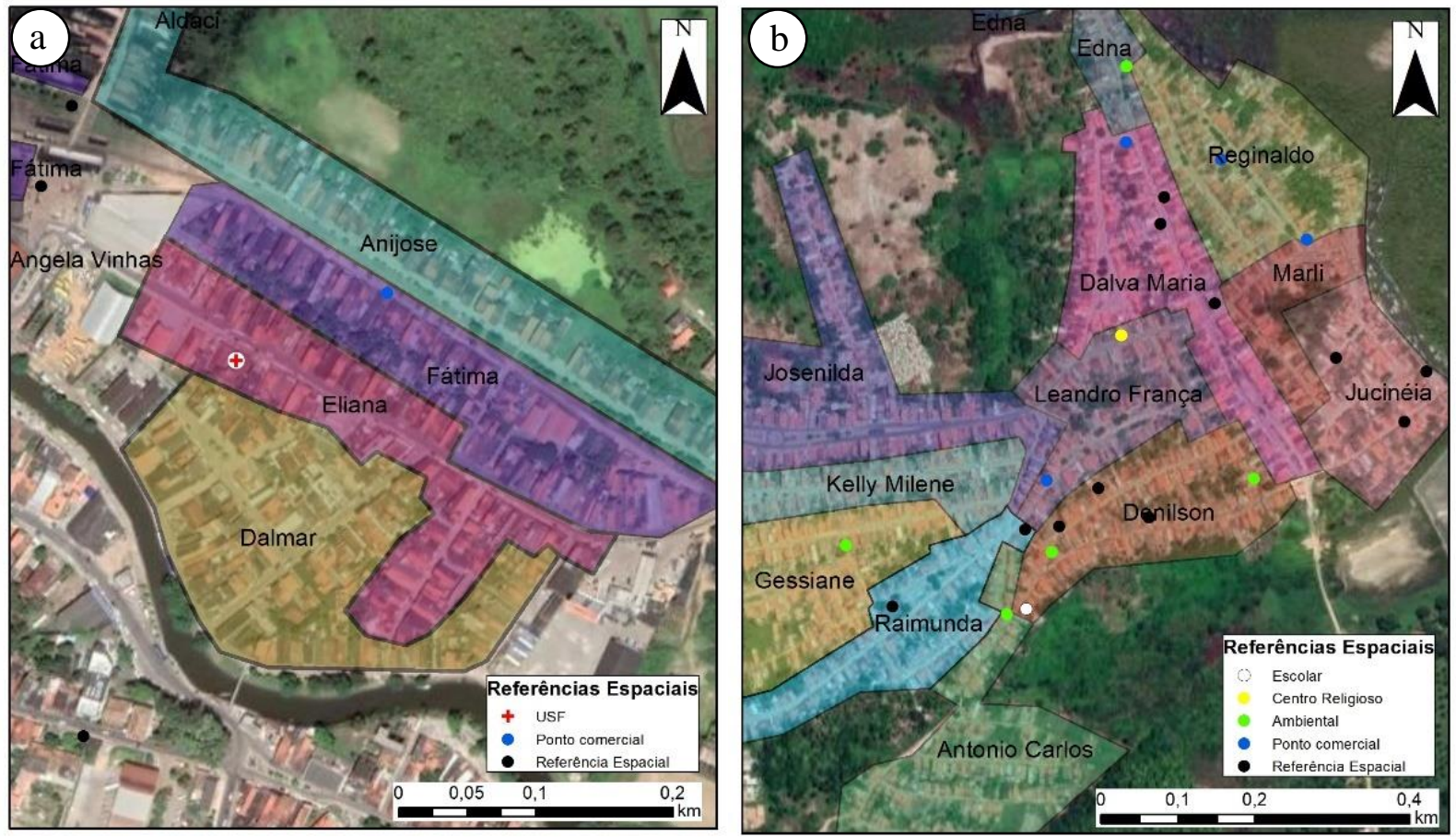

Fonte: Os autores (2021).

Figura 11 - Resultado do mapeamento participativo em Santo Amaro - BA.

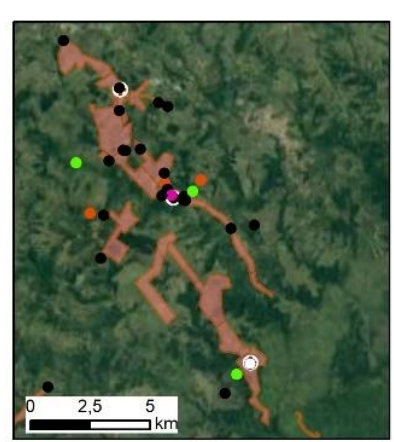
$38^{\circ} 42^{\prime} 30^{\prime \prime} \mathrm{W}$ $38^{\circ} 42^{\prime} \mathrm{O}^{\prime \prime} \mathrm{W}$ $38^{\circ} 41^{\prime} 30^{\prime \prime W}$
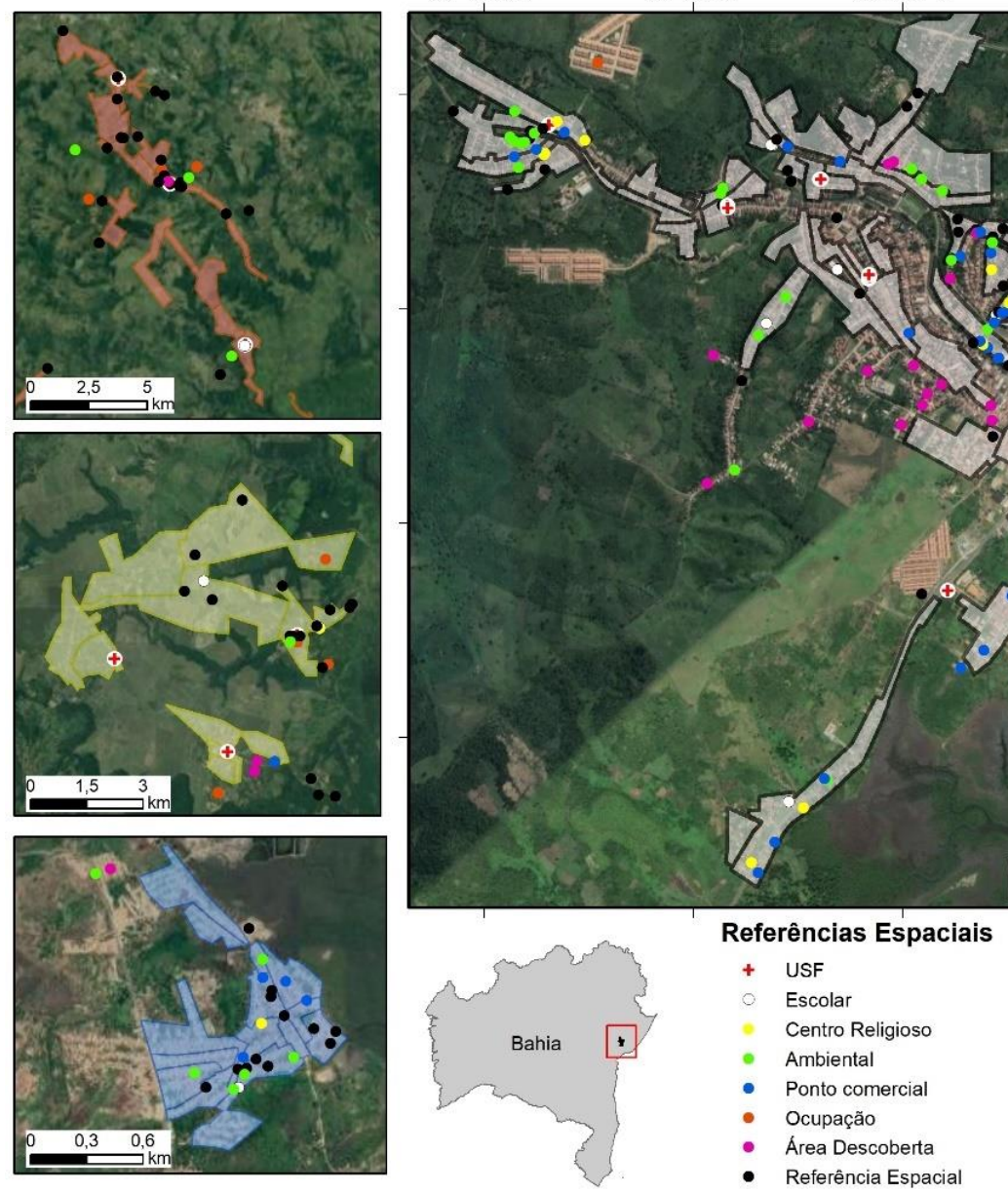

Poligonais

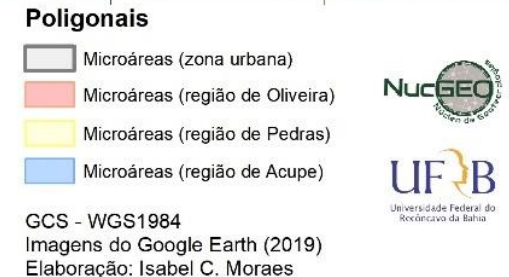

Fonte: Os autores (2021). 
Elaborado em ambiente de SIG, este produto cartográfico (figura 11) apresenta as microáreas inseridas no contexto urbano, e as poligonais geograficamente periféricas, que são apresentadas em quadros (de cima para baixo), que correspondem respectivamente às áreas de abrangência das USF de Oliveira dos Campinhos, USF de Pedras, e USF de Acupe.

Às bases digitais integradas em SIG, somam-se 448 pontos de referência registrados no mapeamento: 81 pontos pra indicação dos limites entre as microáreas, 57 pontos para a categoria 'ambiental', 24 para 'centro religioso', 21 pontos para a categoria 'escolar', 49 'pontos comerciais', e 10 pontos para 'ocupação'. Foram registrados 156 pontos para referenciar toponímias, como becos, ruas e fazendas. A categoria 'área descoberta' foi evidenciada por 22 pontos e 6 poligonais registradas. É válido ressaltar que esta categoria é de fácil verificação devido aos "vazios" de registros na imagem. Paradoxalmente, um dos principais resultados do mapeamento é a ausência de registros espaciais indicando áreas sem acompanhamento regular dos ACS, sendo de extrema relevância à gestão da atenção básica de saúde do município.

\subsection{Feedback}

Os produtos cartográficos gerados, que incluem a integração de todos os registros espaciais resultantes do mapeamento participativo, foram compartilhados em meio digital para todos os atores envolvidos, ACS, coordenadoras da Atenção Básica e Secretaria Municipal de Saúde, através de link que pode ser acessado por diversos aplicativos, como Google Earth, GPS Essential, Map Marker e outros. Este procedimento permitirá a constante atualização dos territórios pelos profissionais de saúde. Também serão disponibilizados mapas em formato de imagem (de extensão jpeg ou pdf) para cada uma das UBS.

\section{CONSIDERAÇÕES FINAIS}

O uso de tecnologias de geolocalização em dispositivos móveis e de aplicativos integrados a sistema de posicionamento global e imagens de satélite mostrou-se como um recurso adequado e de baixo custo para o mapeamento participativo. A interpretação das imagens do Google Earth em meio digital favoreceu a identificação dos territórios de ação das equipes que compõem a ESF, mesmo em locais com restrição de acesso a serviços de internet. O reconhecimento dos objetos na imagem se deu, em grande medida, pela apropriação do território pelos ACS.

Assim, a proposta das oficinas e do treinamento enquanto instrumento de autonomia aos atores sociais, foi mais satisfatório no processo de navegação com o uso das imagens de satélite do que na delimitação dos territórios em meio digital. Apesar disso, foi possível verificar em cada equipe pelo menos um profissional de saúde que se destacou no treinamento, sendo capaz de realizar a metodologia sem a presença de um mediador. Tal fato torna possível certa autonomia na atualização de dados cartográficos do município. São os dados permanentes dos ACS que poderão apontar, desde que interpretados corretamente e utilizado pelos tomadores de decisão, áreas mais vulneráveis ou áreas de maior ocorrência de enfermidades, partindo do conhecimento pessoal destes agentes para a ação em planejamento de intervenções públicas.

Em grande parte, o processo de territorialização foi oportunizado pela relação de pertencimento e a experiência do cotidiano dos ACS nos territórios de ação da ESF, reforçando o papel dos atores sociais no processo de mapeamento. Os mapas analógicos mostraram-se importantes durante as oficinas, pois evidencia a experiência prévia dos mapeadores tanto na elaboração quanto na leitura de produtos cartográficos. E, também, contribuíram para legitimar o conhecimento dos ACS, elucidado pelo processo de transcrição das feições espaciais para o ambiente digital. A abordagem metodológica oportunizou a capacitação, instrumentalização e democratização de recursos de GPS/GNSS e geotecnologias de fácil acesso, e mostra-se como um caminho para a sistematização de dados na saúde pública. Cabe reforçar, de acordo com Canto (2017), que as novas tecnologias espaciais se configuram em uma nova linguagem de comunicação cartográfica, tanto na produção quanto no consumo dos mapas. As novas formas de interação que permeiam a variedade de recursos de mídia em diferentes interfaces, devem conduzir a uma linguagem mais contemporânea também na cartografia digital. 
Cabe salientar que somente mapear não soluciona os problemas locais, mas deve haver um empenho da esfera decisória para colocar em prática programas de atendimento às fragilidades apontadas neste tipo de mapeamento, considerando que essas informações georreferenciadas podem ser cruzadas com variáveis ambientais, sociais ou demográficas do município estudado, norteando ações de saúde pública. Incentiva-se que novas metodologias envolvendo experiências participativas sejam criadas, e novos estudos sejam realizados, incorporando tecnologias de geolocalização e popularizando o uso desta importante ferramenta.

\section{Agradecimentos}

Aos Agentes Comunitários de Saúde, Coordenadoras da Atenção Básica das Unidades Básicas de Saúde, à Secretaria Municipal de Saúde de Santo Amaro (BA) e à Secretaria Estadual de Saúde (SESAB Salvador/BA). Ao Conselho Nacional de Desenvolvimento Científico e Tecnológico - CNPq pelo apoio financeiro - processo n. 421167/2018-1. À Universidade Federal do Recôncavo da Bahia - UFRB, ao apoio institucional de bolsa de iniciação científica - PIBIC/UFRB - à graduanda Débora Santos Passos, ao Grupo de Estudos em Ciências Ambientais - GECAM/UFRB, e ao Núcleo de Geotecnologias - NUCGEO/UFRB.

\section{Contribuição dos Autores}

O mapeamento participativo foi coordenado pela autora Isabel Cristina Moraes e realizado com a participação dos autores Gustavo Luís Schacht, Shanti Nitya Marengo e Débora Santos Passos durante as oficinas. A estruturação de dados em SIG e a elaboração dos produtos cartográficos foram realizados pela autora Isabel Cristina Moraes. Os autores Shanti Nitya Marengo, Gustavo Luís Schacht e Débora Santos Passos estiveram envolvidos na redação e revisão do manuscrito.

\section{Conflitos de Interesse}

Os autores declaram que não há conflitos de interesse.

\section{Referências}

ALMEIDA, R.D. Cartografia escolar. São Paulo: Contexto. 2014. 224 p.

ARAÚJO, F.E.; ANJOS, R.S.; ROCHA FILHO, G.B. Mapeamento participativo: conceitos, métodos e aplicações. Boletim de Geografia, Maringá, v. 35, n. 2, p. 128-140, 2017. DOI. 10.4025/bolgeogr.v35i2.31673.

BARACELLOS, C.; RAMALHO, W. Situação atual do geoprocessamento e da análise de dados espaciais em saúde no Brasil. Informática Pública, v. 4, n. 2, p. 221-230, 2002.

BEZERRA, A.C.V.; BITOUN, J. Metodologia participativa como instrumento para a territorialização das ações da Vigilância em Saúde Ambiental. Ciência \& Saúde Coletiva, v. 22, n. 10, p.3259-3268, 2017. DOI. 10.1590/1413-812320172210.17722017.

BRASIL. Ministério da Saúde. Política Nacional de Atenção Básica. Brasília: Ministério da Saúde, 2012.

BOARD, C. Map reading tasks appropriate in experimental studies in cartographic communication. The Canadian Cartographer, v. 15, n. 1, p. 1-12, 1978. DOI. 10.3138/AG15-V252-3726-W346.

BORGES, K. A. V.; DAVIS JR., C. A.; LAENDER, A. H. F. Modelagem conceitual de dados geográficos. In: CASANOVA, M. A.; CÂMARA, G.; DAVIS JR., C. A.; VINHAS, L.; QUEIROZ, G. (Ed). Bancos de Dados Geográficos, p. 86-136, 2005.

BROWN, G. G.; PULLAR, D. V. An evaluation of the use of points versus polygons in public participation geographic information systems using quasi-experimental design and Monte Carlo simulation. International Journal of Geographical Information Science, v. 26, n. 2, p.231-246, 2012. DOI. 
10.1080/13658816.2011.585139.

BURKE, J.G.; O’CAMPO, P.; PEAK, G.L. GIELEN, A.C.; McDONNEL, K.A.; TROCHIM, W.M.K. An Introduction to Concept Mapping as a Participatory Public Health Research Method. Qualitative Health Research, v. 15, n. 10, p. 1392-1410, December 2005. DOI. 10.1177/1049732305278876.

CANAL, H.; VERDUM, R. Conhecendo e construindo a saúde pelo ambiente: uma proposta de leitura participativa e territorializada em saúde ambiental. Revista Franco-brasilera de Geografia, Confins, n. 35, 2018. DOI. 10.4000/confins. 13137.

CANTO, T.S. Cartography, new technologies and geographic education: theoretical approaches to research the field. International Cartographic Association, n.1, 2017. DOI. 10.5194/ica-proc-1-31-2018.

CARVER, S.; WATSON, A.; WATERS, T.; MATT, R.; GUNDERSON, K.; DAVIS, B. Developing computer-based participatory approaches to mapping landscape values for landscape and resource management. GEERTMAN, S.; STILLWELL, J. (Ed.). Planning support systems best practice and new methods. Dordrecht: Springer, The GeoJournal Library, 2009. p.431-448. DOI. 10.1007/978-14020-8952-7.

CASTELlAR, S.M.V.; JULIASZ, P. C. S. Educação geográfica e pensamento espacial: conceitos e representações. ACTA Geográfica, Boa Vista, Edição Especial 2017, p. 160-178, 2017. DOI. 10.5654/acta.v0i0.4779.

CERTEAU, Michel de. A Invenção do cotidiano: artes do fazer. Rio de Janeiro: Petrópolis, Vozes, 2014.

CHAMBERS, R. Rural Participatory mapping and geographic information system: Whose map? Who is empowered and who disempowered? Who gains and who loses? Electronic Journal on Information Systems in Developing Countries, v. 25, n.2, p. 1-11, 2006. DOI. 10.1002/j.1681-4835.2006.tb00163.x.

CORBETT, J.M.; KELLER, C.P. An Analytical Framework to Examine Empowerment Associated with Participatory Geographic Information Systems (PGIS). Cartographica, v. 40, n. 4, 2005. DOI. 10.3138/J590-6354-P38V-4269.

COLOMBO, V.P. Uso de tecnologias geo-espaciais comuns para o mapeamento de assentamentos informais. In: PESSOA COLOMBO, V.; BASSANI, J.; TORRICELli, G.-P.; ARAÚJO, S. A. de (Orgs.). Mapeamento participativo: tecnologia e cidadania. Primeira edição, 2019 - versão digital. p. 62-72.

DONGUS, S.; NYIKA, D.; KANNADY, K.; MTASIWA, D.; MSHINDA, H.; FILLINGER, U.; DRESCHER, A.W.; CASTRO, M.C.; KILLEEN, G. Participatory mapping of target areas to enable operational larval source management to suppress malaria vector mosquitoes in Dar es Salaam, Tanzania. International Journal of Health Geographics, Londres, v. 6, n. 37, p. 6-37, 2007. DOI. 10.1186/1476-072X-6-37.

DOWNS, R.; STEA, D. Cognitive maps and spatial behaviour: Process and products. In: DOWNS, R.; STEA, D. (Eds.). Image and environment. Londres: Edward Arnold, 1973. p. 312-317. DOI. 10.1002/9780470979587.ch41.

FONSECA, E.S.; LEITE, D.V.B.; MOURA, A.C.M.; COELHO, G.L.L.M. Estudo da percepção espacial em representações cartográficas realizadas por agente de saúde de Ouro Preto, MG. Revista Brasileira de Cartografia, v. 62, n. 3, p. 517-525, 2010.

FORNACE, K.M.; SURENDRA, H.; ABDIN, T.R.; REYES, R.; MACALINAO, M.L.M.; STRESMAN, G.; LUCHAVEZ, J. Use of mobile technology-based participatory mapping approaches to geolocate health facility attendees for disease surveillance in low resource settings. International Journal of Health Geographics, Londres, p. 17-21, 2018. DOI. 10.1186/s12942-018-0141-0.

FOLEY, R. Assessing the applicability of GIS in a health and social care setting: Planning services for informal carers in East Sussex, England. Social Science \& Medicine, v. 55, p. 79-96, 2002. DOI. 10.1016/s02779536(01)00208-8.

GHOSE, R. Use of Information Technology for Community Empowerment: Transforming Geographic Information Systems. Community Information Systems Transactions in GIS, v. 5, n. 2, p. 141-163, 2001. DOI. 10.1111/1467-9671.00073. 
GOldSTEIN, R. A.; BARCEllos, C.; MAGAlHÃES, M.A.F.M.; GRACIE, R.; VIACAVAL, F. A experiência de mapeamento participativo para a construção de uma alternativa cartográfica para a ESF. Ciência \& Saúde Coletiva, v. 18, n.1, p. 45-56, 2013. DOI. 10.1590/S1413-81232013000100006.

GOLDSTEIN, R. A. A cartografia na Estratégia de Saúde da Família: instrumentos para incorporação do território na Atenção Primária à Saúde. 2012. 63 f. Tese (Doutorado) - Escola Nacional de Saúde Pública Sergio Arouca, Rio de Janeiro, 2012.

HAESBAERT, R. Regional-global: dilemas da região e da regionalização na geografia contemporânea. Rio de Janeiro: Bertrand Brasil, 2010.

HELWITT, R.J.; BOER, C.; FLACKE, J. Participatory development of digital support tools for local-scale energy transitions: Lessons from two European case studies. Global Transitions, v. 2, p. 138-149, 2020. DOI. 10.1016/j.glt.2020.07.003.

ISHIKAWA, T. Satellite Navigation and Geospatial Awareness: Long-Term Effects of Using Navigation Tools on Wayfinding and Spatial Orientation. The Professional Geographer, v. 71, n. 2, p. 197-209, 2019. DOI. 10.1080/00330124.2018.1479970.

MARTINUCI, O.S. Cartografia da Saúde: Alguns apontamentos. In: RIBEIRO, E.A.W. (Org.). A cartografia na geografia da saúde. Santa Catarina, Instituto Federal Catarinense, 2019. p. 6-21. DOI. 10.21166/9788556440433.

MATSUMOTO, P.S.S.; D’ANDREA, L.A.Z. O uso da escala geográfica na saúde pública: as escalas da leishmaniose visceral. Ciência \& Saúde Coletiva, v. 24, n. 10, p. 3825-3836, 2019. DOI. 10.1590/1413812320182410.25452017.

MONKEN, M. Contexto, território e o processo de territorialização de informações: desenvolvendo estratégias pedagógicas para a educação profissional em vigilância em saúde. In: BARCELLOS, C. (Org.) A geografia e o contexto dos problemas de saúde. Rio de Janeiro: ABRASCO, 2008. p. 141-164.

MONKEN, M.; BARCELLOS, C. Vigilância em saúde e território utilizado: possibilidades teóricas e metodológicas. Caderno Saúde Pública, v.21, n.3, p.898-906, 2005. DOI. 10.1590/S0102311 X2005000300024.

NASCIMENTO, K.N.F.; NASCIMENTO, K.N.F. Mapeamento participativo: mapa dos equipamentos de saúde do município de Conde-PB. In: Simpósio Brasileiro de Ciências Geodésicas e Tecnologias da Geoinformação, IV, 2012. Anais... Recife - PE, 2012. p. 1-5.

OLIVEIRA, L. Estudo Metodológico e Cognitivo do Mapa. In: ALMEIDA, R. D. de. (Org.). Cartografia Escolar. São Paulo: Contexto, 2014. p. 15-41.

RZESZEWSKI, M.; KOTUS, J. Usability and usefulness of internet mapping platforms in participatory spatial planning. Applied Geography, v. 103, p. 56-69, 2019. DOI. 10.1016/j.apgeog.2019.01.001.

SAADALLAH, D.M. Utilizing participatory mapping and PPGIS to examine the activities of local communities. Alexandria Engineering Journal, n. 59, p. 263-274, 2020. DOI. 10.1016/j.aej.2019.12.038.

SANTOS, M. A natureza do espaço: técnica e tempo, razão e emoção. São Paulo: Editora da Universidade de São Paulo, 2006.

SHEPPARD, E. (2008). Produção de conhecimento através do Sistema de Informações Geográficas Crítico: genealogia e perspectivas. In: ACSELRAD, H. (Org.) Cartografias Sociais e Território. Rio de Janeiro: Universidade Federal do Rio de Janeiro, Instituto de Pesquisa e Planejamento Urbano e Regional, p. 113152.

SPEAKE, J.; AXON, S. "I Never Use 'Maps' Anymore": Engaging with Sat Nav Technologies and the Implications for Cartographic Literacy and Spatial Awareness. The Cartographic Journal, Liverpool, v. 49, n. 4, p. 326-33, 2012. DOI. 10.1179/1743277412Y.0000000021.

TALEN, E. Bottom-up GIS: A new tool for individual and group expression in participatory planning. Journal of American Planning Association, v. 66, n. 3, p. 279-294, 2000. DOI. 10.1080/01944360008976107. 
VAJJHALA, S.P. Integrating GIS and Participatory Mapping in Community Development Planning. ESRI International User Conference, Sustainable Development and Humanitarian Affairs Track, San Diego, CA, July 2005.

VERPLANKE, J.; McCALL, M.K.; UBERHUAGA, C.; RAMBALDI, G.; HAKLAY, M. A Shared Perspective for PGIS and VGI. The Cartographic Journal, Liverpool, p. 1-10, 2016. DOI. 10.1080/00087041.2016.1227552.

\section{Biografia do autor principal}

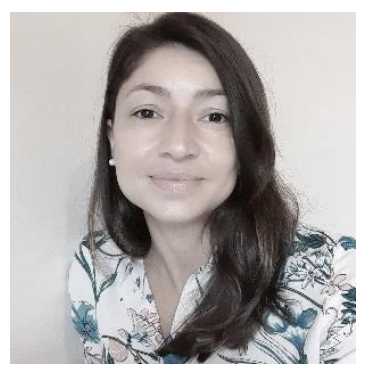

Isabel Cristina Moraes, natural de Pirassununga - SP. Geógrafa formada pela Universidade Estadual Paulista (UNESP/Rio Claro), com mestrado em Geologia Regional e Doutorado em Geografia pela mesma instituição. Tem experiência profissional em Cartografia e Geoprocessamento, atuando principalmente em mapeamentos temáticos por Sensoriamento Remoto e Modelagem Ambiental em Sistemas de Informação Geográfica - SIG. Atualmente, atua como docente na Universidade Federal do Recôncavo da Bahia - UFRB (CCAAB/Cruz das Almas), na área de Geografia Física com ênfase em Geotecnologias.

Esta obra está licenciada com uma Licença Creative Commons Atribuição 4.0 Internacional - CC BY. Esta licença permite que outros distribuam, remixem, adaptem e criem a partir do seu trabalho, mesmo para fins comerciais, desde que lhe atribuam o devido crédito pela criação original. 